\title{
Identifikasi Morfometri dan Pola Ruang Taman Setra di Kecamatan Kuta Utara, Kabupaten Badung, Provinsi Bali
}

\author{
Putu Wiprah Baskara ${ }^{1}$, Anak Agung Gede Sugianthara ${ }^{1 *}$, I Gusti Agung Ayu Rai Asmiwyati ${ }^{1}$
}

1. Prodi Arsitektur Lanskap, Fakultas Pertanian, Universitas Udayana, Jl. P.B. Sudirman, Denpasar, Indonesia

*E-mail: sugianthara@unud.ac.id

\begin{abstract}
Morphometry And Setra Space Pattern Identification In North Kuta Sub-District, Badung Regency, Bali Province. Bali island has three types of garden. One of garden's types that exist in Bali is setra. Setra garden in Bali had been used for spiritual ceremonies like Ngaben. There were more than 1500 setra gardens that had not been yet identified in Bali. Therefore, identifying, collecting data, and mapping of setras garden were needed in analyzing the setras. Setras garden in which located in North Kuta sub-district was chosen in this research because there was not any database yet which was related to the setras especially for its space pattern and morphometry. This research aimed to identify the morphometry, space pattern, factors that affecting space pattern, and utilization of the setras in North Kuta sub-district. The research method used was survey method. This research used descriptive qualitative, and quantitative analisys. In the results, this research found that Kerobokan traditional village had the highest percentage number of setra garden which was $38,1 \%$. Setra Tuka was located in the higest elevation $(122,34 \mathrm{msal})$, while the $80 \%$ of setras was in the flat topography. The average area of setras garden in North Kuta was about 0,12 Ha. Direction of centre, and southeast was the most setras position (19\%). The whole setras garden in North Kuta applied Tri Mandala concept as its space pattern and all of its space pattern was affected by tradition factor. For setras additional utilization, Caru and Ngereh have the highest percentage, while Ngelungah and Ngelangkir is more attractive activity for tourism.
\end{abstract}

Keyword : identification, morphometry, utilization, space pattern, setra

\section{Pendahuluan}

Taman-taman di Pulau Bali ada yang terbentuk secara alami, semi alami, dan ada pula secara buatan. Taman pantai, taman danau, dan taman pegunungan adalah contoh dari taman alami di Pulau Bali. Taman Tirtha Gangga, Taman Kertha Gosa, Tirtha Empul, dan Taman Goa Gajah adalah contoh taman buatan manusia sebagai hasil peninggalan kerajaan di jaman dahulu. Areal persawahan subak dan kuburan (setra) adalah contoh taman semi alami di Pulau Bali. Taman setra di Bali adalah taman yang berfungsi untuk melaksanakan upacara Ngaben (upacara pembakaran jenazah di Bali), dan penguburan jenazah serta ritual lainnya. Terdapat lebih dari 1500 taman setra yang belum teridentifikasi dengan baik, juga belum diketahui secara detil keberadaan setra tersebut. Identifikasi, pendataan, pemetaan, dan pembinaan pengelolaan taman setra masih diperlukan untuk menjaga kelestarian dari taman setra tersebut dan juga ikut mendukung program pemerintah Provinsi Bali untuk mewujudkan "Bali Pulau Taman" (Sugianthara et al., 2017).

Taman setra memiliki kaitan dengan pariwisata. Wisata yang dihadirkan pada taman setra dengan daya tarik kegiatan upacara ritual dan aktivitas keagamaannya yaitu upacara ngaben disimpulkan sebagai salah satu daya tarik wisata. Para wisatawan tertarik terhadap kegiatan ini karena di daerah mereka tidak terdapat upacara serupa (Puspa et al., 2019). Kabupaten Badung adalah wilayah di Pulau Bali dengan kepadatan usaha pariwisata tinggi. Kegiatan pariwisata tinggi di Kabupaten Badung merupakan cerminan wakil dari keadaan Pulau Bali secara umum. Dipilihnya setra yang berlokasi pada desa adat di Kecamatan Kuta Utara dikarenakan belum adanya database mengenai informasi mendalam khususnya tentang pola ruang dan morfometri pada taman setra setempat. Selain itu, terdapat upacara Ngaben di taman setra pada Kecamatan Kuta Utara. Pembuatan database/pusat informasi tentang taman setra merupakan salah satu upaya pelestarian budaya. Pelestarian budaya dapat dilakukan dengan 2 (dua) cara yaitu culture experience (menuju langsung ke tempat kejadian/mendapatkan pengalaman dari kebudayaan tersebut) dan culture 
knowledge (membuat sebuah pusat informasi mengenai suatu kebudayaan sebagai pusat edukasi atau sumber pariwisata) (Hastuti et al., 2013). Hasil penelitian ini diharapkan dapat memperkaya metode pelestarian budaya secara culture knowledge yaitu dengan cara membuat sebuah database/pusat informasi. Informasi yang terkandung di dalam database ini yaitu pola ruang, morfometri, dan pemanfaatan taman setra pada desa adat di Kecamatan Kuta Utara. Dengan dimilikinya data mengenai taman setra lebih mendalam pada desa adat di Kecamatan Kuta Utara maka akan dapat meningkatkan upaya konservasi budaya seperti mempertahankan unsur-unsur pola ruang taman setra jikalau terdapat penataan ulang di areal taman setra dan memberikan informasi mengenai luasan taman setra, dan sekaligus berpotensi menjadi DTW (Destinasi Pariwisata). Tujuan dari penelitian ini adalah untuk mengidentifikasi morfometri, pola ruang, faktor-faktor yang mempengaruhi pola ruang, dan pemanfaatan/fungsi taman setra pada desa adat di Kecamatan Kuta Utara.

\section{Metode}

\subsection{Lokasi Penelitian}

Penelitian ini dilaksanakan di 21 taman setra yang terletak di 8 (delapan) wilayah desa adat di Kecamatan Kuta Utara, yaitu Desa Adat Dalung, Padangluwih, Tuka, Kerobokan, Berawa, Tandeg, Padonan, dan Canggu (Gambar 1).

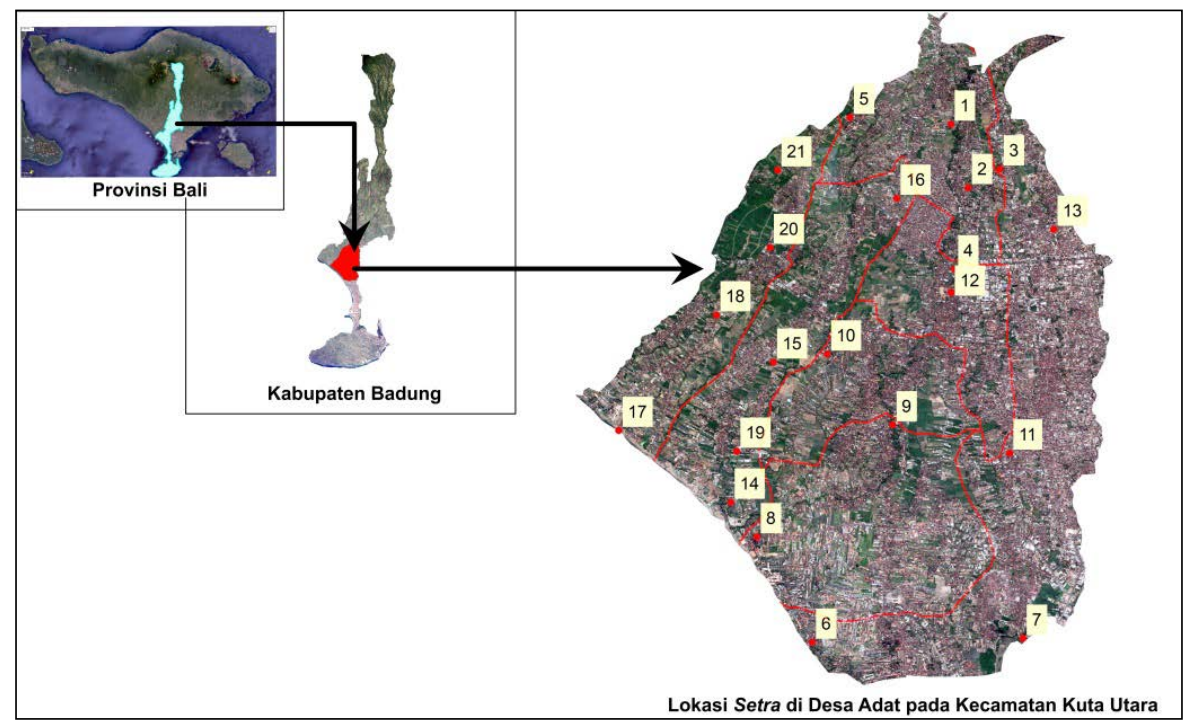

Gambar 1. Lokasi Taman Setra pada desa adat di Kecamatan Kuta Utara (Google Earth, 2020) Keterangan :
1. Setra Dalung
2. Setra Celuk
3. Setra Kuanji
4. Setra Tegaljaya
8. Setra Batubelig
9. Setra Dukuh
15. Setra Tandeg
10. Setra Banjaranyar
16. Setra Padonan
5. Setra Tuka
11. Setra Teges
17. Setra Canggu
6. Setra Kayu Aya
12. Setra Kerobokan
18. Setra Dukuh Pipitan
19. Setra Tegalgundul
7. Setra Umadui-Kerobokan
13. Setra Robokan
20. Setra Kahyangan Babakan
14. Setra Berawa
21. Setra Umadui-Canggu

\subsection{Waktu Penelitian}

Penelitian ini berlangsung selama 8 (delapan) bulan dari bulan Juli 2019 hingga Maret 2020.

\subsection{Bahan dan Alat}

Penelitian ini menggunakan beberapa alat seperti: GPS, balpoin, kertas, dan komputer dengan software AutoCAD, ArcMap, Google Earth, Pages, dan Keynote, serta bahan berupa peta wilayah dan tapak taman setra pada desa adat di Kecamatan Kuta Utara. 


\subsection{Metode Penelitian}

Penelitian ini menggunakan metode survei dengan teknik pengumpulan data observasi lapangan, wawancara, penyebaran kuesioner, dan studi pustaka. Survei lapang digunakan pada penelitian ini untuk mendapatkan data biofisik, yaitu: data pola ruang, morfometri, dan elemen taman setra. Kegiatan observasi pada penelitian ini meliputi mengobservasi setiap taman setra pada setiap desa adat di Kecamatan Kuta Utara yang berkaitan dengan pola ruang, elemen taman, morfometri, dan fungsi serta kondisi taman setranya masing-masing. Kuesioner dibuat untuk mendapatkan data mengenai pemanfaatan taman setra di masing-masing desa adat. Responden yang terpilih secara purposive random sampling berjumlah 30 orang yang merupakan masyarakat yang tinggal pada desa adat di Kecamatan Kuta Utara dengan jenis kuesioner tertutup. Penyebaran kuesioner dilaksanakan dengan tahapan pertama-tama menentukan topik pertanyaan dan menentukan karakteristik responden, membuat daftar pertanyaan, memberikan kepada masyarakat secara langsung di masing-masing kelurahan di Kecamatan Kuta Utara dengan jumlah merata sejumlah 5 (lima) kuesioner di masing-masing kelurahan, dan selanjutnya disusun dan dianalisis. Penelitian ini memilih pihak Bendesa Adat dan Pemangku Pura Dalem setempat sebagai informan kunci untuk diwawancarai. Studi pustaka dalam penelitian ini bersumber dari jurnal, buku, peraturan-peraturan, perundang-undangan, internet, dan dokumen lainnya.

\subsection{Analisis Data dan Pengolahan Data}

Penelitian ini menggunakan data primer seperti: pola ruang, morfometri, dan pemanfaatan taman setra pada desa adat di Kecamatan Kuta Utara. Penelitian ini menggunakan model analisis data deskriptif kualitatif, dan deskriptif kuantitatif. Deskripsi data yang diperoleh dari kuesioner disajikan dalam bentuk persentase (\%). Perhitungan persentase menggunakan rumus dari (Sudjana, 2002). Analisis ini digunakan untuk menghasilkan data persentase keseluruhan penelitian dari hasil temuan data, seperti: persentase dasar pembagian ruang taman setra. Berikut merupakan rumus dari (Sudjana, 2002):

$P=\frac{f}{N} \times 100 \%$

Keterangan :

$\mathrm{P}=$ persentase

$f=$ responden

$\mathrm{N}=\Sigma$ total responden

\section{Hasil dan Pembahasan}

\subsection{Gambaran Umum}

Kecamatan Kuta Utara adalah sebuah kecamatan di Kabupaten Badung, Bali, Indonesia. Luasnya adalah 418,52 km². Pada tahun 2018, penduduknya berjumlah 134,73 jiwa (BPS Kabupaten Badung, 2019). Curah hujan rata-rata bulanan di Kecamatan Kuta Utara adalah 244,09 mm, dengan arah angin rata-rata bulanan adalah ke arah timur. Suhu udara rata-rata bulanan di Kecamatan Kuta Utara adalah $27,2^{\circ} \mathrm{C}$ dan kecepatan angin rata-rata bulanannya adalah 6,58 knot (BMKG, 2019). Sebagian besar struktur tanah di Kabupaten Badung tergolong jenis produk gunung api muda yang terdiri dari endapan lahar, tufa pasiran, dan breksi vulkanik (Bappeda Kabupaten Badung, 2017). Terkait pariwisata, dari tahun 2011-2015 rata-rata sejumlah 650,854,8 wisatawan nusantara mengunjungi Kabupaten Badung (BPS Kabupaten Badung, 2019).

\subsection{Morfometri Taman Setra pada Desa Adat di Kecamatan Kuta Utara}

Morfometri memiliki arti suatu kegiatan penghitungan dan analisis secara kuantitatif pada bentukan permukaan bumi. Contoh bentukan bumi yang diukur adalah batas wilayah, ketinggian tempat, volume/luas, kemiringan lereng (topografi), profil, dan tekstur bentang alam (Namoua et al., 2017). Morfometri taman setra pada desa adat di Kecamatan Kuta Utara dikaji dengan 5 (lima) variabel yaitu: lokasi setra, elevasi, topografi, luas, dan posisi taman setra di masing-masing desa adat. Dijumpai 21 taman setra pada 8 (delapan) desa adat di Kecamatan Kuta Utara. Hasil observasi data morfometri taman setra pada masing-masing desa adat di Kecamatan Kuta Utara tertuang pada Tabel 1. 
Tabel 1. Morfometri Taman Setra pada Desa adat di Kecamatan Kuta Utara

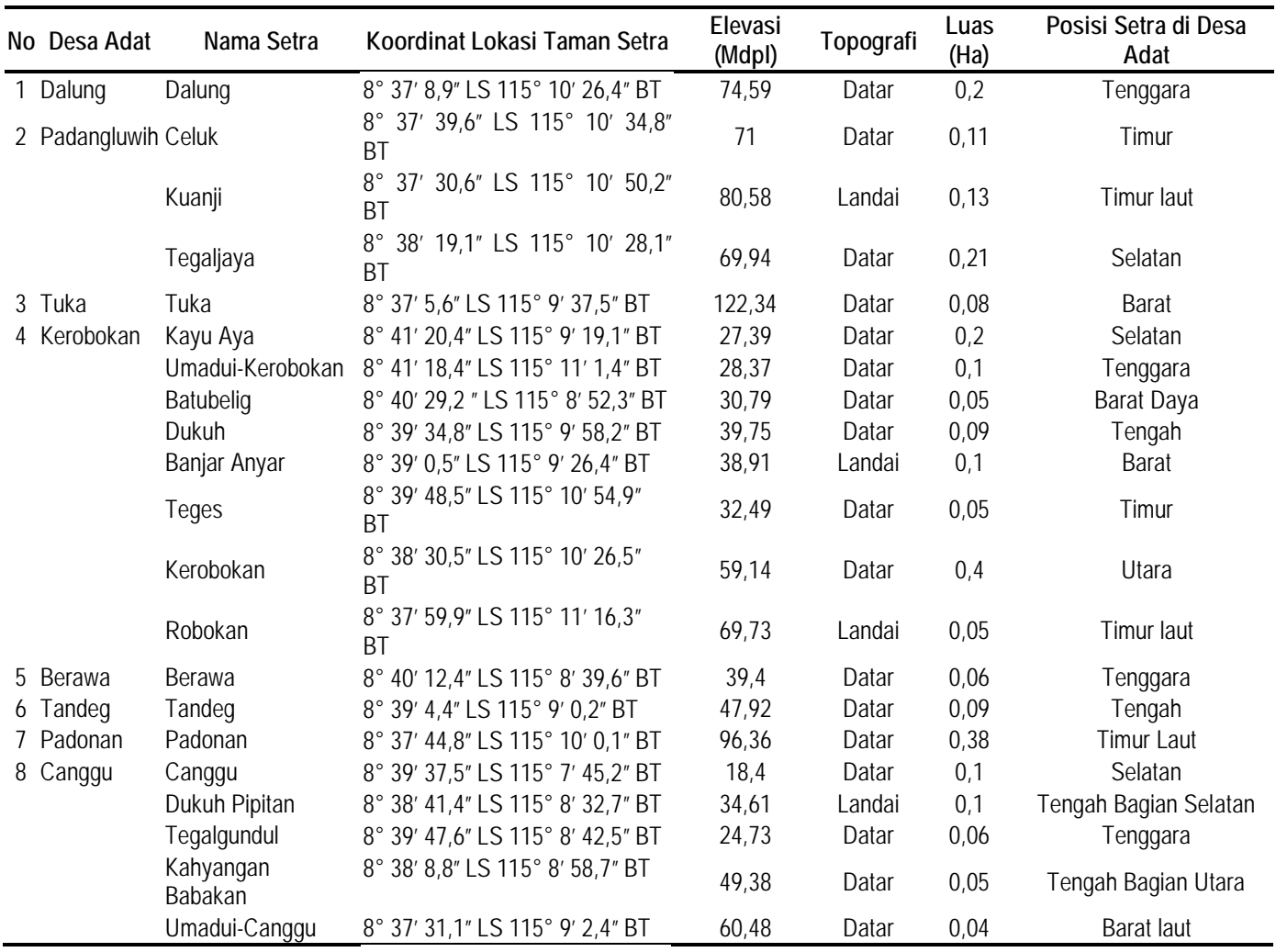

Morfometri berdasarkan lokasi penyebaran taman setra menunjukkan bahwa di Desa Adat Kerobokan memiliki lokasi jumlah taman setra terbanyak yaitu 8 (delapan) taman setra atau dengan persentase jumlah taman setra 38,2\% (Gambar 2). Taman setra di Desa Adat Kerobokan memiliki persentase jumlah taman setra tertinggi dikarenakan luasnya areal Desa Adat Kerobokan sehingga jumlah taman setra disesuaikan agar masyarakat mudah mengakses taman setranya masing-masing. Taman setra dengan elevasi tertinggi yaitu Setra Tuka mencapai 122,34 mdpl dan setra dengan elevasi terendah yaitu Setra Canggu dengan elevasi 18,4 mdpl (Gambar 3). Taman Setra Tuka memiliki persentase paling tinggi di antara taman setra lain terkait elevasi dikarenakan Taman Setra Tuka terletak di wilayah Desa Adat Tuka yang memang termasuk desa adat dengan elevasi tertinggi di antara desa adat lainnya di wilayah Kecamatan Kuta Utara.

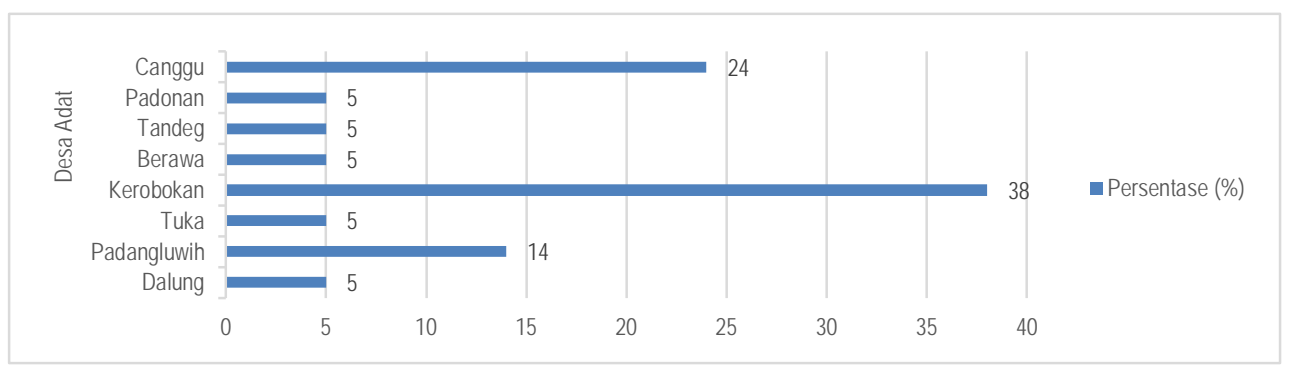

Gambar 2. Grafik Jumlah Taman Setra di Masing-masing Desa adat pada Kecamatan Kuta Utara

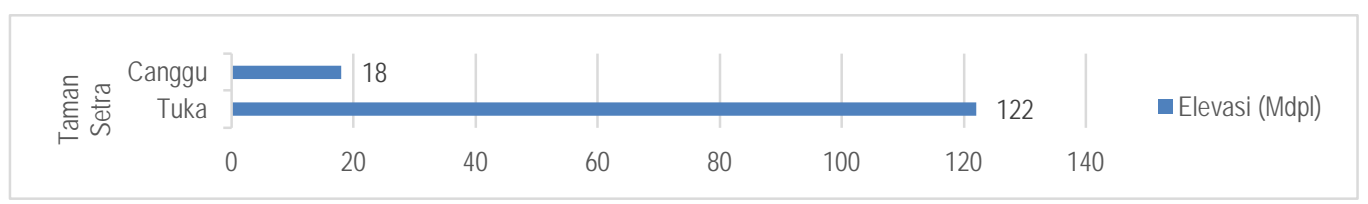

Gambar 3. Grafik Elevasi Tertinggi dan Terendah Taman Setra 
Morfometri taman setra berdasarkan topografinya menunjukkan bahwa sebagian besar (80\%) taman setra di Kecamatan Kuta Utara memiliki topografi datar yaitu padan Taman Setra Dalung, Celuk, Tegaljaya, Tuka, Kayu Aya, Umadui-Kerobokan, Batubelig, Dukuh, Teges, Kerobokan, Berawa, Tandeg, Padonan, Canggu, Tegalgundul, Kahyangan Babakan, dan Umadui-Canggu serta sisanya (20\%) memiliki topografi yang landai yaitu pada Taman Setra Kuanji, Banjar Anyar, Robokan, dan Dukuh Pipitan (Gambar 4). Taman setra dengan topografi datar memiliki persentase lebih tinggi daripada taman setra dengan topografi landai karena wilayah desa adat di Kecamatan Kuta Utara terletak di daerah dataran sehingga memiliki tingkat kemiringan yang rendah.

Morfometri berdasarkan luas setra menunjukkan bahwa taman setra di Kecamatan Kuta Utara memiliki rata-rata luas $0,12 \mathrm{Ha}$. Taman setra dengan nilai luasan tertinggi yaitu Setra Kerobokan dengan luas $0,4 \mathrm{Ha}$. Setra dengan nilai luasan terendah yaitu Setra Umadui Canggu dengan luas 0,04 Ha (Gambar 5). Taman Setra Kerobokan memiliki luasan paling tinggi dibandingkan dengan taman setra lainnya dikarenakan Desa Adat Kerobokan memang memiliki luas wilayah dan sebaran jumlah krama desa adat tertinggi dibandingkan desa adat lainnya di Kecamatan Kuta Utara.

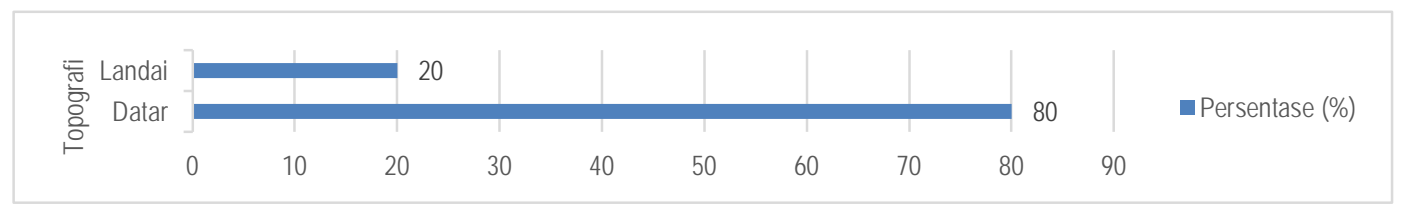

Gambar 4. Grafik Keragaman Topografi Taman Setra pada desa adat di Kecamatan Kuta Utara

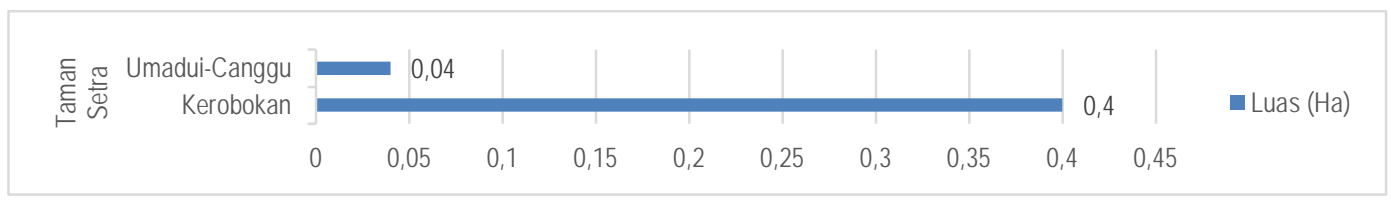

Gambar 5. Grafik Luasan Tertinggi dan Terendah Taman Setra di Kecamatan Kuta Utara

Morfometri berdasarkan letak setra di desa adat menunjukkan bahwa letak taman setra di tengah, dan tenggara desa adat memiliki persentase 19\%, di timur laut, dan selatan desa adat sebesar 14,2\%, di timur, dan barat desa adat sebesar 9,5\%, di utara, barat laut, dan barat daya desa adat 4,8\% (Gambar 6). Morfometri berdasarkan letak setra di desa adat memiliki nilai tertinggi yaitu di tengah, dan tenggara desa adat. Taman setra yang terletak di tengah desa adat memiliki nilai yang tinggi karena taman setra di desa adat tersebut menyesuaikan terhadap luasan desa adat dan persebaran permukiman sehingga masyarakat mudah dalam mengaksesnya (Desa Kala Patra), dan taman setra yang terletak di bagian tenggara desa adat memiliki nilai yang tinggi dikarenakan mengikuti kearifan lokal Tri Mandala/Tri Angga.



Gambar 6. Persentase Posisi Taman Setra pada Masing-masing Desa Adat di Kecamatan Kuta Utara

Terkait status kepemilikan lahan taman setra di masing-masing desa adat. Hasil wawancara mengenai status kepemilikian lahan menunjukkan bahwa seluruh taman setra pada desa adat di Kecamatan 
Kuta Utara kecuali Taman Setra Dalung dan Taman Setra Padonan telah memiliki sertifikat kepemilikan lahan dengan persentase 90,5\% sedangkan taman setra yang belum memiliki sertifikat memiliki persentase 9,5\%. Taman setra yang telah memiliki sertifikat lahan telah diproses sertifikat lahannya oleh pengelola taman setra bersangkutan baik secara swadaya maupun lewat proyek prona dari pemerintah (Gambar 7).

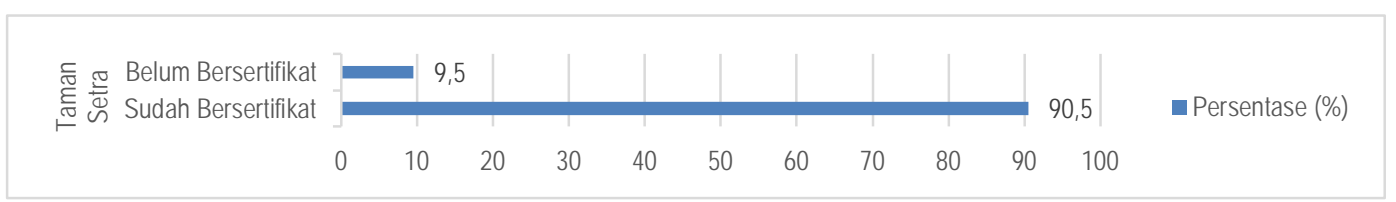

Gambar 7. Grafik Status Kepemilikan Lahan Taman Setra di Kecamatan Kuta Utara.

\subsection{Pola Ruang dan Faktor Pengaruh Pola Ruang Taman Setra}

Pola ruang dari taman setra pada desa adat di Kecamatan Kuta Utara disajikan pada Tabel 2, serta gambar pola ruang taman setra pada desa adat di Kecamatan Kuta Utara pada Gambar 8.

Tabel 2. Pola Ruang dan Faktor Pengaruh Pola Ruang Taman Setra pada Desa Adat di Kecamatan Kuta Utara

\begin{tabular}{|c|c|c|c|c|c|c|c|c|c|c|c|c|c|}
\hline \multirow{3}{*}{ No } & \multicolumn{13}{|c|}{ Pola Ruang } \\
\hline & \multirow[t]{2}{*}{ Setra } & \multicolumn{2}{|c|}{ Landasan } & \multicolumn{3}{|c|}{ Dasar Pembagian } & \multicolumn{4}{|c|}{ Jenis Setra } & \multicolumn{3}{|c|}{ Faktor Pengaruh } \\
\hline & & TM/TA & DK & B & $\mathrm{K}$ & U & SG & SR & SB & SM & $\mathrm{S}$ & $\mathbf{T}$ & $\mathrm{KI}$ \\
\hline 1 & Dalung & $\sqrt{ }$ & - & - & - & $\checkmark$ & $\checkmark$ & $\checkmark$ & - & - & - & $\checkmark$ & - \\
\hline 2 & Celuk & $\checkmark$ & - & - & - & $\checkmark$ & $\checkmark$ & $\checkmark$ & - & - & - & $\checkmark$ & - \\
\hline 3 & Kuanji & $\checkmark$ & - & - & - & $\checkmark$ & $\checkmark$ & $\checkmark$ & - & - & - & $\checkmark$ & - \\
\hline 4 & Tegaljaya & $\checkmark$ & - & - & - & $\checkmark$ & $\checkmark$ & $\checkmark$ & - & - & - & $\checkmark$ & - \\
\hline 5 & Tuka & $\checkmark$ & - & - & - & $\checkmark$ & $\checkmark$ & $\checkmark$ & - & - & - & $\checkmark$ & - \\
\hline 6 & Kayu Aya & $\checkmark$ & - & - & - & $\checkmark$ & $\checkmark$ & $\checkmark$ & $\checkmark$ & - & - & $\checkmark$ & - \\
\hline 7 & Umadui-Kerobokan & $\checkmark$ & - & - & $\checkmark$ & $\checkmark$ & $\checkmark$ & $\checkmark$ & - & $\checkmark$ & - & $\checkmark$ & - \\
\hline 8 & Batubelig & $\checkmark$ & - & - & $\checkmark$ & $\checkmark$ & $\checkmark$ & $\checkmark$ & $\checkmark$ & $\checkmark$ & - & $\checkmark$ & - \\
\hline 9 & Dukuh & $\checkmark$ & - & - & $\checkmark$ & $\checkmark$ & $\checkmark$ & $\checkmark$ & - & $\checkmark$ & - & $\checkmark$ & - \\
\hline 10 & Banjar Anyar & $\checkmark$ & - & - & $\checkmark$ & $\checkmark$ & $\checkmark$ & $\checkmark$ & - & $\checkmark$ & - & $\checkmark$ & - \\
\hline 11 & Teges & $\checkmark$ & - & - & - & $\checkmark$ & $\checkmark$ & $\checkmark$ & - & - & - & $\checkmark$ & - \\
\hline 12 & Kerobokan & $\checkmark$ & - & $\checkmark$ & $\checkmark$ & $\checkmark$ & $\checkmark$ & $\checkmark$ & - & $\checkmark$ & - & $\checkmark$ & - \\
\hline 13 & Robokan & $\checkmark$ & - & - & - & $\checkmark$ & $\checkmark$ & $\checkmark$ & - & - & - & $\checkmark$ & - \\
\hline 14 & Berawa & $\checkmark$ & - & - & - & $\checkmark$ & $\checkmark$ & $\checkmark$ & $\checkmark$ & - & - & $\checkmark$ & - \\
\hline 15 & Tandeg & $\checkmark$ & - & - & $\checkmark$ & $\checkmark$ & $\checkmark$ & $\checkmark$ & - & $\checkmark$ & - & $\checkmark$ & - \\
\hline 16 & Padonan & $\checkmark$ & - & - & $\checkmark$ & $\checkmark$ & $\checkmark$ & $\checkmark$ & - & $\checkmark$ & - & $\checkmark$ & - \\
\hline 17 & Canggu & $\checkmark$ & - & - & - & $\checkmark$ & $\checkmark$ & $\checkmark$ & $\checkmark$ & - & - & $\checkmark$ & - \\
\hline 18 & Dukuh Pipitan & $\checkmark$ & - & - & $\checkmark$ & $\checkmark$ & $\checkmark$ & - & $\checkmark$ & $\checkmark$ & - & $\checkmark$ & - \\
\hline 19 & Tegalgundul & $\checkmark$ & - & - & - & $\checkmark$ & $\checkmark$ & $\checkmark$ & $\checkmark$ & - & - & $\checkmark$ & - \\
\hline 20 & Kahyangan Babakan & $\checkmark$ & - & - & $\checkmark$ & $\checkmark$ & $\checkmark$ & $\checkmark$ & - & $\checkmark$ & - & $\checkmark$ & - \\
\hline 21 & Umadui-Canggu & $\checkmark$ & - & - & - & $\checkmark$ & $\checkmark$ & - & $\checkmark$ & - & - & $\checkmark$ & - \\
\hline
\end{tabular}

Keterangan: TM/TA (Tri Mandala/Tri Angga), DK (Desa Kala Patra), B (Banjar), K (Kasta), U (Umur), SG (Setra Gede/Kuburan Umum), SR (Setra Rare/Kuburan Anak-anak), SB (Setra Bebajangan/Kuburan Remaja), SM (Setra Menak/Kuburan Bagi Masyarakat Berkasta), S (Sosial), T (Tradisi), KI (Kearifan Lokal).

Pola ruang berdasarkan Tri Mandala/Tri Angga menjadi dasar penataan seluruh taman setra pada desa adat di Kecamatan Kuta Utara. Tri Mandala adalah sebuah falsafah Umat Hindu di Bali yang memuat mengenai pembagian ruang menjadi tiga yaitu Utama Mandala, Madya Mandala, dan Nista Mandala (Gelebet et al., 2002). Di setra, Utama Mandala digunakan untuk mendirikan bangunan Pura Prajapati. Pura Prajapati biasa berada pada bagian utara, timur atau timur laut setra. Pada bagian Madya Mandala berfungsi sebagai pusat kegiatan manusia terkait upacara Pitra Yadnya. Pada bagian Nista Mandala berfungsi untuk membakar, dan membuang sampah-sampah kegiatan di setra (Gambar 8). 


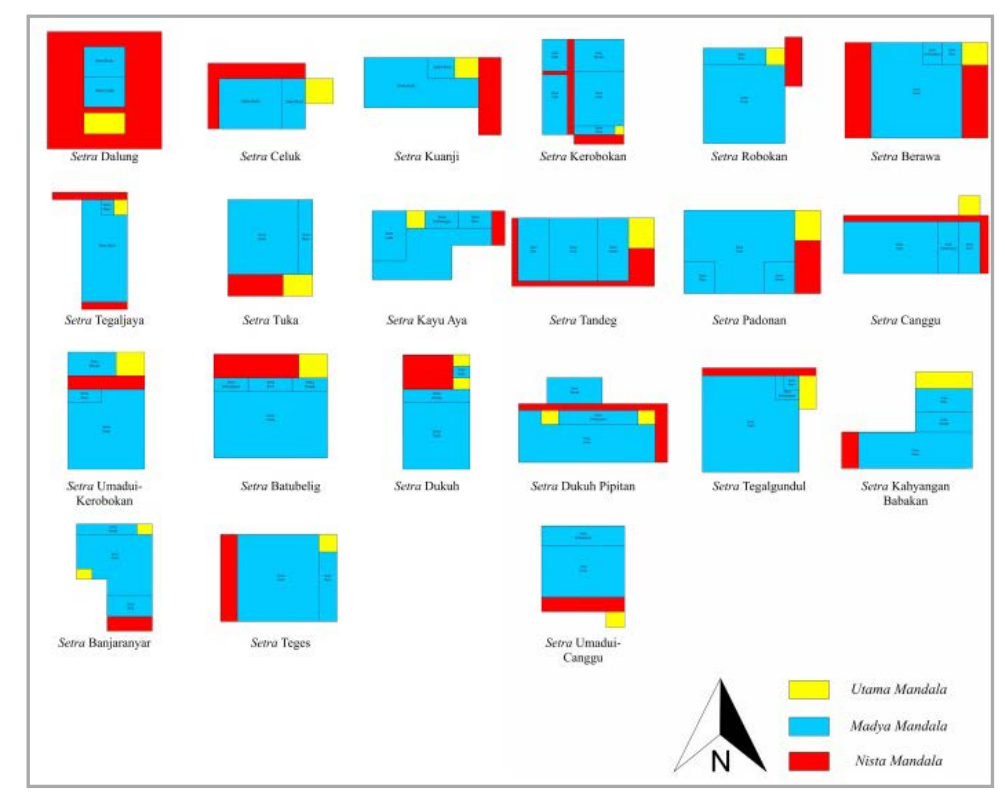

Gambar 8. Pola Ruang Taman Setra pada desa adat di Kecamatan Kuta Utara

Tidak satupun setra yang menggunakan konsep dengan landasan Desa Kala Patra (waktu tempat dan keadaan) pada desa adat di Kecamatan Kuta Utara. Pola ruang dengan pembagian berdasarkan banjar (Banjar adalah suatu perkumpulan masyarakat dalam suatu kesatuan lingkungan tertentu, dengan batas wilayah teritorial sebagai pengikat warga anggotanya sesuai dengan peraturan banjar yang ditetapkan (awigawig) (Noviasi et al., 2015)) hanya dianut oleh Setra Kerobokan dengan persentase 4\%. Pembagian berdasarkan kasta dianut oleh Setra Umadui Kerobokan, Batubelig, Dukuh, Banjar Anyar, Kerobokan, Tandeg, Padonan, Dukuh Pipitan, dan Kahyangan Babakan (38\%). Pembagian berdasarkan umur dianut oleh semua setra pada desa adat di Kecamatan Kuta Utara (100\%) (Gambar 9). Pembagian ruang dalam taman setra pada desa adat di Kecamatan Kuta Utara disesesuaikan oleh kebutuhan masing-masing desa adat.

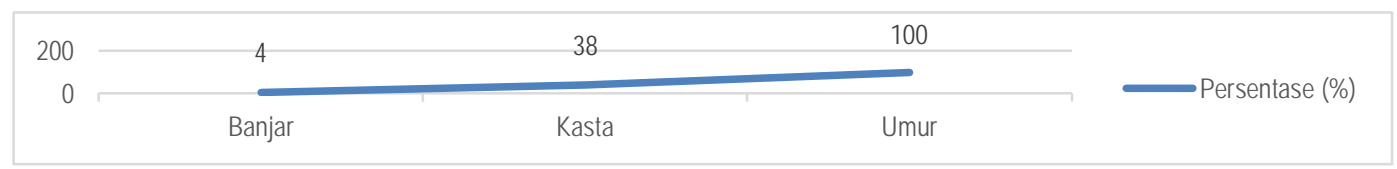

Gambar 9. Grafik Dasar Pembagian Ruang Taman Setra

Pola ruang setra dengan jenis setra gede terdapat di semua setra pada desa adat di Kecamatan Kuta Utara dengan persentase 100\%. Dengan jenis setra rare hanya tidak terdapat di Setra Dukuh Pipitan dan Setra Umadui Canggu dengan persentase 9\%. Dengan jenis setra bebajangan terdapat di Setra Kayu Aya, Batubelig, Berawa, Canggu, Dukuh Pipitan, Tegalgundul, dan Umadui Canggu dengan persentase 33\%. Dengan jenis Setra Menak terdapat di Setra Umadui Kerobokan, Kerobokan, Batubelig, Dukuh, Banjaranyar, Tandeg, Padonan, Dukuh Pipitan, dan Kahyangan Babakan dengan persentase 42\% (Gambar 10). Jenis-jenis setra disesuaikan oleh keperluan masing-masing desa adat, namun jenis Setra Gede sudah dipastikan ada di setiap taman setra. Kearifan lokal adalah pandangan hidup dan ilmu pengetahuan serta berbagai strategi kehidupan yang berwujud aktivitas yang dilakukan oleh masyarakat lokal dalam menjawab berbagai masalah dalam pemenuhan kebutuhan mereka (Fajarini, 2014). Faktor Sosial merupakan sekelompok orang yang sama-sama mempertimbangkan secara dekat persamaan di dalam status atau penghargaan komunitas yang secara terus-menerus bersosialisasi di antara mereka sendiri baik secara formal dan informal (Sawitri et al., 2013). Faktor tradisi memiliki persentase tertinggi terkait faktor yang mempengaruhi pola ruang dalam taman setra karena masyarakat pada desa adat di Kecamatan Kuta Utara hanya mengikuti hal-hal yang telah dilaksanakan secara turun-temurun oleh leluhur-leluhur mereka (Gambar 11). 


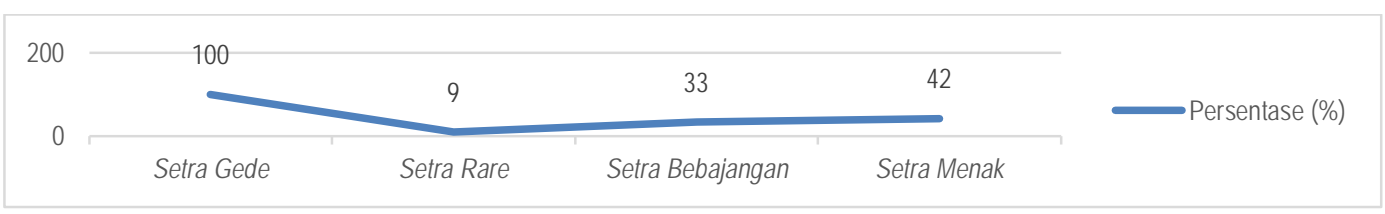

Gambar 10. Grafik Jenis Setra

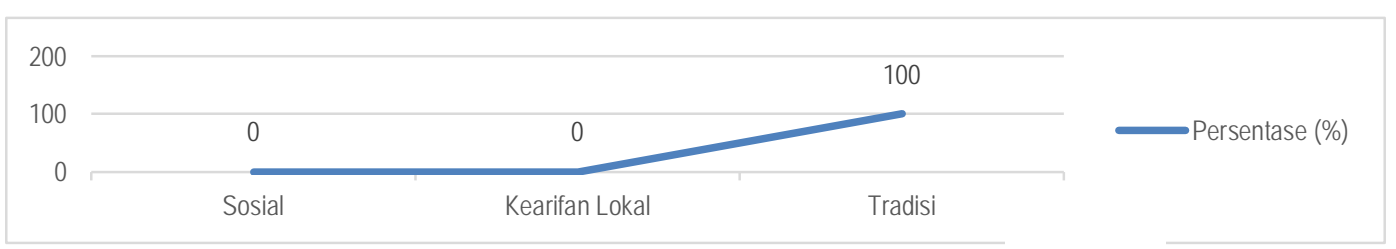

Gambar 11. Grafik Faktor yang Mempengaruhi Pola Ruang T

\subsubsection{Elemen Taman Setra}

Setiap taman setra pada desa adat di Kecamatan Kuta Utara terdapat berbagai elemen di dalamnya. Salah satu elemen di taman setra adalah elemen lunak (softscape). Elemen lunak yang dibahas kali ini adalah vegetasi jenis pohon. Variasi elemen pepohonan taman setra pada desa adat di Kecamatan Kuta Utara cukup variatif. Berikut merupakan hasil observasi elemen lunak jenis pohon taman setra pada desa adat di Kecamatan Kuta Utara dalam bentuk grafik persentase jumlah tanaman jenis pohon masing-masing disajikan pada Gambar 12.

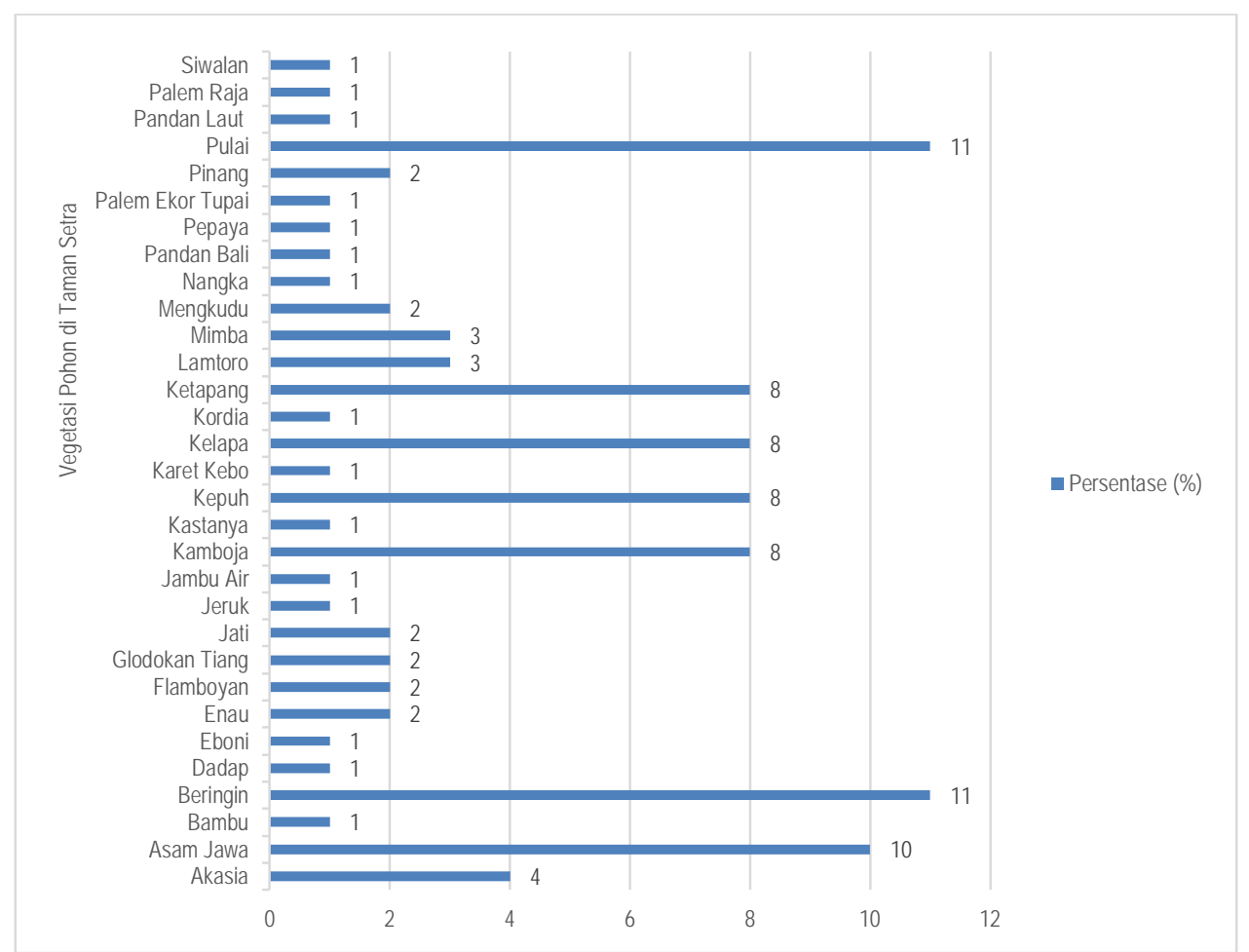

Gambar 12. Persentase Keberadaan Vegetasi Pohon pada Taman Setra di Kecamatan Kuta Utara

Gambar 12 menunjukkan bahwa Pohon Beringin (Ficus benjamina) dan Pohon Pulai (Alstoneia scholaris) memiliki persentase paling tinggi dibandingkan dengan jenis pohon lainnya, yaitu masing-masing memiliki persentase sebesar 11\%. Pohon Beringin dan Pohon Pulai sering terdapat di taman setra karena digunakan sebagai tanaman perindang, memiliki fungsi sebagai sarana upakara, dan ada yang dipercaya sebagai obat seperti kulit kayu Pohon Pulai. Fungsi pohon Pulai dalam kegiatan upacara yaitu sebagai 
bahan pembuatan Tapel (topeng sakral), sedangkan pohon Beringin digunakan dalam upacara Ngangget Don Bingin. Pohon-pohon lainnya ditanam sebagai tanaman peneduh, namun ada beberapa jenis pohon yang tumbuh secara alami yang memiliki nilai kebudayaan.

\subsection{Pemanfaatan Sekunder Taman Setra pada desa adat di Kecamatan Kuta Utara}

Upacara Ngaben merupakan upacara yang utama di setiap taman setra dan juga merupakan upacara yang menarik perhatian para wisatawan. Kali ini yang dibahas adalah pemanfaatan sekunder dari taman setra. Berdasarkan grafik pada Gambar 13, Upacara Ngereh (upacara penyucian benda yang akan digunakan salam pembuatan topeng Betara Randa secara berwujud dan tidak berwujud) memiliki persentase 33,3\%, Caru Pengalang Sasih, dan Caru Laba Karma Durga dapat dikategorikan menjadi satu jenis upacara yaitu Caru (upacara yang dilaksanakan oleh Umat Hindu di Bali sebagai bentuk harmonisasi antar manusia dengan alam) dengan persentase $33,4 \%$. Upacara Ngelungah (upacara kematian untuk bayi yang tali pusarnya belum terlepas), Ngelangkir (upacara kematian untuk bayi yang sudah terlepas tali pusarnya, namun belum mengalami tanggal gigi) memiliki persentase masing-masing 16,7\%. Dari upacaraupacara tersebut yang menarik wisatawan adalah Upacara Ngelungah dan Ngelangkir, karena upacara ini selain dilaksanakan di setra, juga dilaksankan di pantai dengan berbagai kegiatan keagamaannya, sehingga menarik rasa ingin tahu wisatawan.

\begin{tabular}{|r|cccc}
\hline 50 & 33,3 & 33,3 & 16,7 & 16,7 \\
0 & Ngereh & Caru & Ngelungah & Ngelangkir
\end{tabular}

Gambar 13. Grafik Pemanfaatan Taman Setra

Hasil penyebaran kuesioner menunjukkan berdasarkan aspek sosial budaya pemanfaatan taman setra pada desa adat di Kecamatan Kuta Utara adalah untuk melaksanakan Ngaben sejumlah 17 responden (57\%), dan penguburan jenazah sejumlah 13 responden (43\%). Tidak ada satupun responden memilih jawaban sebagai tempat pertunjukkan calonarang (pertunjukkan seni tari di Pulau Bali yang biasa diadakan di setra atau Pura Dalem), dan tempat Pecaruan sasih ke-6 (Gambar 14). Berdasarkan aspek ekologi pemanfaatan taman setra sebagai ruang terbuka hijau (RTH) sejumlah 20 responden (67\%), sebagai pengatur iklim mikro sejumlah 4 responden (13\%), sebagai konservasi air dan tanah sejumlah 3 responden (10\%), dan sebagai habitat flora dan fauna sejumlah 3 responden (10\%) (Gambar 15).

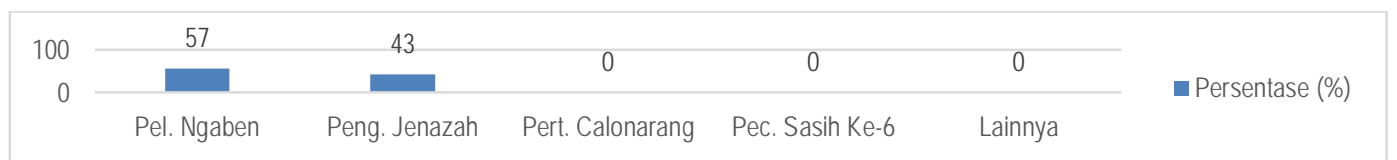

Gambar 14. Grafik Pengetahuan Masyarakat Mengenai Pemanfaatan Taman Setra (Aspek Sosial Budaya)

\begin{tabular}{|c|c|c|c|c|c|c|}
\hline \multirow{3}{*}{$\begin{array}{r}100 \\
0\end{array}$} & 67 & 13 & 10 & 10 & 0 & \multirow{3}{*}{ - Persentase (\%) } \\
\hline & & - &  & $\square$ & & \\
\hline & RTH & P. Iklim Mikro & K. Air dan Tanah & H. Flora dan Fauna & Lainnya & \\
\hline
\end{tabular}

Gambar 15. Grafik Pengetahuan Masyarakat Mengenai Pemanfaatan Taman Setra (Aspek Ekologi)

Berdasarkan aspek estetika pemanfaatan taman setra sebagai daya tarik wisata (DTW) sejumlah 5 responden (17\%), sebagai tempat rekreasi sejumlah 4 responden (13\%), sebagai taman sejumlah 15 responden (50\%), dan sebagai tempat pelestarian tanaman langka sejumlah 6 orang (20\%) (Gambar 16). Hasil tersebut menunjukkan bahwa pemanfaatan taman setra pada desa adat di Kecamatan Kuta Utara berdasarkan aspek sosial budaya memiliki jawaban dengan persentase tertinggi yaitu pelaksanaan upacara 
Ngaben. Berdasarkan aspek ekologi memiliki jawaban dengan persentase tertinggi sebagai ruang terbuka hijau (RTH). Berdasarkan aspek estetika memiliki jawaban dengan persentase tertinggi yaitu taman.

$\begin{array}{rcccc}100 & 17 & 50 & 20 & 0\end{array} \quad$ = Persentase (\%)

Gambar 16. Grafik Pengetahuan Masyarakat Mengenai Pemanfaatan Taman Setra (Aspek Estetika)

\section{Simpulan dan Saran}

\subsection{Simpulan}

Berdasarkan hasil penelitian ini dapat ditarik simpulan sebagai berikut:

1. Morfometri berdasarkan lokasi taman setra menunjukkan bahwa jumlah taman setra tertinggi terdapat di Desa Adat Kerobokan memiliki delapan buah taman setra (dengan persentase 38,2\%), elevasi taman setra bervariasi antara 18,00--122,34 mdpl (adalah Taman Setra Tuka dan terendah pada Taman Setra Canggu), topografinya sebagian besar (80\%) datar dan sisanya (20\%) landai, luasan taman setra tertinggi dimiliki oleh Taman Setra Kerobokan (0,4 Ha), dan yang tersempit pada Taman Setra Umadui-Canggu (0,04 Ha). Posisi taman setra dominan terletak di tengah dan tenggara desa adat. Hampir seluruh taman setra di Kecamatan Kuta Utara telah memiliki sertifikat kepemilikan lahan, kecuali Taman Setra Dalung, dan Taman Setra Padonan. Jumlah taman setra terbanyak cenderung berada di Desa Adat Kerobokan. Taman-taman setra pada desa adat di Kecamatan Kuta Utara cenderung memiliki topografi datar. Taman Setra Kerobokan memiliki kecenderungan taman setra dengan luasan tertinggi, dan taman Setra Tuka memiliki kecenderungan taman setra dengan elevasi tertinggi. Status kepemilikan lahan taman setra cenderung telah memiliki sertifikat kepemilikan lahan.

2. Pola ruang taman setra pada masing-masing desa adat di Kecamatan Kuta Utara berdasarkan landasan pembagian ruang didasari oleh kearifan lokal Tri Mandala/Tri Angga sebesar 100\%, pembagian ruang berdasarkan banjar memiliki persentase $4 \%$, berdasarkan kasta memiliki persentase $3,8 \%$, dan berdasarkan umur sebesar $100 \%$. Pola ruang berdasarkan jenis setra gede memiliki persentase $100 \%$, berdasarkan jenis setra rare sebesar $9 \%$, berdasarkan jenis setra bebajangan sebesar $33 \%$, dan berdasarkan jenis setra menak sebesar $42 \%$.

3. Faktor yang mempengaruhi pola ruang taman setra pada setiap desa adat di Kecamatan Kuta Utara berdasarkan faktor tradisi (sebesar 100\%). Faktor tradisi yang dimaksudkan yaitu pola ruang di taman setra bersangkutan memiliki pola ruang sedemikian rupa yang berdasarkan kepercayaan secara turun-temurun. Vegetasi pohon paling dominan pada taman setra desa adat di Kecamatan Kuta Utara yaitu Pohon Pulai (Alstonia scholaris) dan Pohon Beringin (Ficus benjamina).

4. Pemanfaatan taman setra di desa adat di Kecamatan Kuta Utara untuk kegiatan Upacara Ngereh memiliki persentase 33,4\%, Caru dengan persentase 33,4\%. Upacara Ngelungah, Ngelangkir memiliki persentase masing-masing $16,7 \%$. Pemanfaatan pada aspek sosial budaya, kegiatan pelaksanaan upacara ngaben memiliki persentase $57 \%$, penguburan jenazah $43 \%$. Berdasarkan aspek ekologi, sebagai ruang terbuka hijau memiliki persentase $67 \%$, sebagai pengatur iklim mikro 13\%, sebagai konservasi air dan tanah, dan habitat flora dan fauna masing-masing sebesar $10 \%$. Berdasarkan aspek estetika, sebagai daya tarik wisata sebesar $17 \%$, sebagai tempat rekreasi sebesar $13 \%$, sebagai taman sebesar $50 \%$, dan sebagai tempat pelestarian tanaman langka sebesar $20 \%$.

\subsection{Saran}

Berdasarkan hasil penelitian ini dirumuskan saran sebagai berikut:

1. Untuk setiap desa adat di Kecamatan Kuta Utara diharapkan agar dapat terus menjaga dan mengelola keberadaan taman setra di daerahnya masing-masing agar menjadi lebih asri dan apabila memungkinkan dapat melengkapi berbagai fasilitas penunjang kegiatan masyarakat di setra.

2. Perlu dilakukan penelitian lanjutan mengenai taman setra untuk di daerah lain untuk melengkapi database taman setra di Provinsi Bali. 


\section{Daftar Pustaka}

Bappeda Kabupaten Badung. 2017. Rencana Kerja Pemerintah Daerah (RKPD) Kabupaten Badung Tahun 2018.

BMKG. 2019. Pelayanan Jasa Informasi Klimatologi.

BPS Kabupaten Badung. 2019. Kecamatan Kuta Utara Dalam Angka (B. K. Badung (ed.)). BPS Kabupaten Badung.

Fajarini, U. 2014. Peranan Kearifan Lokal Dalam Pendidikan Karakter. Sosio Didaktika: Social Science Education Journal 1(2):123-124.

Gelebet, I. N., Meganada, I. W., Yasanegara, I. M., Sutriya, I. M., \& Surata, I. N. 2002. Arsitektur Tradisional Daerah Bali. Badan Pengembangan Kebudayaan dan Pariwisata Bali.

Hastuti, K., Hidayat, E. Y., \& Rahmawan, E. 2013. Purwarupa Tangible Cultural Heritage Documentation Berbasis Database Multimedia. Jurnal Techno.Com 12(4):188-197.

Namoua, F., Manengkey, H. W. K., \& Rampengan, R. M. 2017. Morfometri Lereng Gisik Di Pantai Tumpaan Kecamatan Tumpaan Kabupaten Minahasa Selatan. Jurnal Pesisir Dan Laut Tropis 1(2):14-19.

Noviasi, N. K. P., Waleleng, G. J., \& Tampi, J. R. (2015). Fungsi Banjar Adat Dalam Kehidupan Masyarakat Etnis Bali Di Desa Werdhi Agung, Kecamatan Dumoga Tengah, Kabupaten Bolang Mongondow Provinsi Sulawesi Utara. Jurnal Acta Diurna IV(3):1-10.

Puspa, I. A. T., \& Saitya, I. B. S. (2019). Ngaben sebagai Daya Tarik Pariwisata. Jurnal Ilmiah Pariwisata Agama Dan Budaya 4(1):37-45.

Sawitri, Y., Hidayat, W., \& Nurseto, S. (2013). Pengaruh Kualitas Produk, Promosi, Faktor Sosial Dan Faktor Psikologi Terhadap Keputusan Pembelian Sepedamotormatic Yamahamio (Studi Pada Yamaha Agungmotor Semarang). Journal of Social and Politic 2(2):1-9.

Sudjana. (2002). Metode Statistika. Tarsito.

Sugianthara, A. A. G., Sarwadana, S. M., Lila, I. K. A., \& Sudarsana, A. A. G. D. (2017). Identifikasi dan Morfometri Taman Setra di Kecamatan Ubud. Jurnal Arsitektur Lanskap 3(1):87-88. 